\title{
Modelação da Contribuição de Fatores Influenciadores do Risco de Infeção por SARS-CoV-2 em Ambientes Interiores
}

\author{
Modelling the Contribution of Factors Influencing the Risk \\ of SARS-CoV-2 Infection in Indoor Environments
}

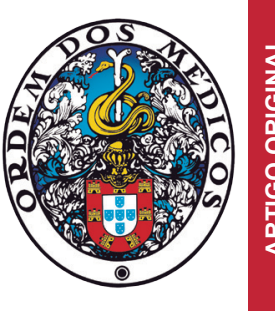

\author{
Susana Marta ALMEIDA $\triangle 1$, João SOUSA² \\ Acta Med Port 2021 Dec;34(12):815-825 - https://doi.org/10.20344/amp.15982
}

\section{RESUMO}

Introdução: O presente trabalho estima o risco de infeção por SARS-CoV-2 em ambientes interiores onde a elevada densidade de ocupação resulta numa probabilidade acrescida de contágio, como escolas, escritórios, supermercados, restaurantes e ginásios.

Material e Métodos: Foram testadas várias condições nos espaços interiores, tais como a utilização e eficácia de máscaras, a ventilação, a utilização de equipamentos que permitem uma assepsia do ar recorrendo a filtros HEPA, a densidade de ocupação e o tempo de permanência nos espaços, tendo sido utilizado um modelo baseado na dispersão de partículas de aerossóis em espaços fechados e na acumulação e inalação destas partículas ao longo do tempo.

Resultados: Os resultados mostraram que a substituição de máscaras sociais por máscaras com classificação FFP2 diminuiu o risco de infeção em $90 \%$ nas escolas. Em escolas com ventilação natural, a abertura das janelas na sua totalidade reduziu o risco de infeção em $64 \%$ comparativamente com o cenário de janelas fechadas. Nos espaços onde a ventilação mecânica é normalmente utilizada, a probabilidade de infeção reduziu significativamente quando os caudais de ar novo regulamentares foram duplicados (redução de $32 \%$ nos escritórios, $42 \%$ nos restaurantes, $24 \%$ nos supermercados e $46 \%$ nos ginásios). A filtragem de ar com filtros HEPA permitiu a redução da probabilidade de infeção em $72 \%$ nas escolas, escritórios e restaurantes e $61 \%$ nos ginásios. O tempo de permanência nos espaços foi também um fator relevante na variação da probabilidade de infeção, principalmente nas escolas onde se verificou que aulas mais curtas e com um maior número de intervalos reduzem o risco de infeção.

Discussão: Os resultados evidenciam a importância de uma adequada ventilação em ambientes fechados, principalmente em locais onde a densidade de ocupação e os tempos de permanência são mais longos, sendo essencial a introdução de ar exterior no interior dos espaços, seja através de meios naturais ou mecânicos. É expectável que os valores de risco de infeção apresentados ao longo do trabalho estejam subvalorizados pelo facto do modelo utilizado apenas considerar a transmissão por partículas inferiores a $10 \mu \mathrm{m}$ e por, ao assumir o distanciamento social, não incluir a transmissão de curto alcance. A vacinação não foi considerada no modelo pelo facto de ainda não estar disponível quando o trabalho foi realizado.

Conclusão: Este estudo vem contribuir para a identificação de medidas que permitem um menor risco de transmissão viral, e consequentemente, uma maior segurança no interior dos espaços fechados.

Palavras-chave: Aerossóis; COVID-19; Fatores de Risco; Qualidade do Ar Interior; SARS-CoV-2; Ventilação

\section{ABSTRACT}

Introduction: This study estimates the risk of aerosol infection by SARS-CoV-2 in indoor environments where high density of occupation results in an increased probability of infection, such as schools, offices, supermarkets, restaurants and gyms.

Material and Methods: In each type of building use, several conditions were simulated, such as the use and effectiveness of masks, ventilation, use of equipment that allows air asepsis using HEPA filters, the density of occupancy and the length of stay in the spaces, using a model based on the dispersion of aerosol particles in indoor spaces and on the accumulation and inhalation of these particles over time.

Results: The results showed that the replacement of social masks by masks with FFP2 classification decreased the risk of infection by $90 \%$ in schools. In schools with natural ventilation, the complete opening of windows reduced the risk of infection by $64 \%$ in comparison with the scenario with closed windows. In spaces where mechanical ventilation is normally used, the probability of infection decreased significantly when the regulatory fresh air flow rates were doubled (reduction of $32 \%$ in offices, $42 \%$ in restaurants, $24 \%$ in supermarkets and $46 \%$ in gyms). The filtration of air with HEPA filters allowed the reduction of the probability of infection by $72 \%$ in schools, offices, and restaurants and $61 \%$ in gyms. The length of stay in the spaces was also a relevant factor in the variation of the probability of infection, especially in schools where it was found that shorter classes with a higher number of intervals reduced the risk of infection. Discussion: The results show the importance of adequate ventilation in indoor environments, especially in places where the density of occupation and the staying times are longer, making the introduction of outside air inside the spaces essential, either through natural or mechanical means. It is expected that the infection risk estimates presented are undervalued because the model only considers transmission by particles smaller than $10 \mu \mathrm{m}$ and does not include the short-range transmission by assuming social distancing. Vaccination was not considered in the model since it was not yet available when the study was carried out.

Conclusion: The present study contributes to the identification of measures that decrease the risk of viral transmission, and consequently provide greater security in indoor spaces.

Keywords: Aerosols; Air Pollution, Indoor; COVID-19; Risk Factors; SARS-CoV-2; Ventilation

\footnotetext{
1. Centro de Ciências e Tecnologias Nucleares. Instituto Superior Técnico. Loures. Portugal.

2. Green Building Energy Efficiency Laboratory Technology. Porto. Portugal.

$\triangle$ Autor correspondente: Susana Marta Almeida. smarta@ctn.tecnico.ulisboa.pt

Recebido: 16 de fevereiro de 2021 - Aceite: 20 de setembro de 2021 - First published: 08 de novembro de 2021 - Online issue published: 02 de dezembro de 2021 Copyright (C) Ordem dos Médicos 2021
} 


\section{INTRODUÇÃO}

A doença COVID-19, declarada em mais de 200 países, já resultou em 230 milhões de casos confirmados e 4713 milhões de mortes em todo o mundo (dados de 24 de setembro de 2021). ${ }^{1}$ Devido à crescente ameaça, a Organização Mundial de Saúde declarou, em março de 2020, a COVID-19 como uma pandemia e uma emergência de saúde pública de âmbito internacional. ${ }^{1} \mathrm{O}$ vírus causador da doença foi identificado como um novo coronavírus altamente infecioso, conhecido como SARS-CoV-2. Cerca de dois anos depois do início da pandemia em Wuhan, o mundo continua perante uma doença infeciosa devastadora, dispondo apenas de dados científicos preliminares para guiar as políticas de combate à pandemia.

\section{Mecanismos de transmissão do SARS-CoV-2}

Desde o início da pandemia, tem havido um intenso debate sobre o modo de transmissão do SARS-CoV-2 com o objetivo de consolidar informação essencial para a definição das melhores práticas para a gestão de pacientes e para a proteção de profissionais de saúde e dos cidadãos em geral.

As infeções respiratórias podem ser transmitidas por partículas de diferentes tamanhos. Tem sido assumido que as gotículas com diâmetro superior a $5 \mu \mathrm{m}$ são produzidas quando um indivíduo tosse, espirra, vomita, cospe e fala, e podem atingir a boca, o nariz e os olhos de quem estiver próximo, dando origem à transmissão de curto alcance. ${ }^{2}$ Devido à sua elevada dimensão, a maioria destas gotículas permanece pouco tempo em suspensão e acaba por depositar-se nas superfícies e objetos a menos de dois metros de distância, ${ }^{3}$ dando depois origem à transmissão por contacto. Por outro lado, as partículas em suspensão com um diâmetro inferior a $5 \mu \mathrm{m}$ não necessitam da tosse ou espirros para serem produzidas, sendo a expiração simples suficiente para a sua emissão. ${ }^{2}$ Estas permanecem no ar por períodos prolongados, desde vários minutos a horas, e viajam vários metros de distância. ${ }^{3} \mathrm{~A}$ comunidade científica tem vindo, cada vez mais, a defender que as partículas em suspensão (aerossóis) têm um papel extremamente relevante na transmissão do vírus de longo alcance $(>2 \mathrm{~m})$, principalmente em locais fechados, com ventilação inadequada, e onde a exposição é prolongada. ${ }^{4-8}$

No entanto, a separação que tem vindo a ser estabelecida entre gotículas e partículas, que define o diâmetro de corte a $5 \mu \mathrm{m}$, é uma simplificação, havendo mesmo autores que defendem que a distinção entre gotículas e partículas, para fins de avaliação dos fenómenos de transmissão, deve ser feita nos $100 \mu \mathrm{m} .{ }^{9}$ É um facto que a capacidade de uma partícula permanecer em suspensão não depende apenas da sua dimensão, mas também da forma como é expelida e das características do ar circundante, tais como a velocidade, turbulência, direção, temperatura e humidade relativa. ${ }^{10}$ Assim, gotículas com diâmetro superior a $5 \mu \mathrm{m}$, dependendo das condições, poderão permanecer mais tempo em suspensão e depositarem-se a distâncias superiores a dois metros. Este comportamento é particularmente impor- tante para partículas com diâmetro até $10 \mu \mathrm{m} .{ }^{10}$ Por outro lado, as partículas de dimensão inferior a $5 \mu \mathrm{m}$ também são responsáveis pela transmissão de curto alcance $(<2 \mathrm{~m})$, até porque estão presentes em concentrações superiores junto das fontes de emissão. ${ }^{11}$ Como resultado das simplificações que têm sido assumidas e do desconhecimento que ainda persiste ao fim de dois anos de pandemia, é inevitável que perdurem incertezas relevantes associadas às práticas de modelação usadas na definição de políticas de controlo e minimização dos impactes do COVID-19.

\section{Implicação na gestão dos espaços públicos interiores}

Qian et a/ ${ }^{12}$ verificaram que em 318 surtos, envolvendo 1245 casos de COVID-19 em 120 cidades da China, 316 ocorreram em espaços interiores, o que indica que a partilha destes espaços acarreta riscos de infeção por SARS-CoV-2. Num espaço fechado, a concentração viral e o risco associado tende a aumentar com o tempo, dependendo muito da razão entre a taxa de emissão ${ }^{13} \mathrm{e} o$ número de renovações de ar novo por hora. ${ }^{14}$ Por outro lado, a ventilação natural ou mecânica é um potencial veículo no transporte de aerossóis, mecanismo este que não é relevante no caso das gotículas de maiores dimensões. 3,15

Para minimizar o risco de infeção, os sistemas de aquecimento, ventilação e ar condicionado (AVAC) dos edifícios precisam de ser adaptados ou operados de forma a responder às novas exigências. Consequentemente, e com o objetivo de dar resposta à COVID-19, várias organizações em todo o mundo publicaram diretrizes para a gestão dos sistemas AVAC. Estas diretrizes recomendam medidas para os sistemas de ventilação existentes, incluindo o seu modo de operação, o tipo de filtros e sistemas de limpeza do ar a utilizar, temperatura e humidade, e funcionamento dos sistemas de recuperação de calor. Guo et al ${ }^{16}$ compararam as diferentes diretrizes e concluíram que todas elas coligem em cinco aspetos fundamentais:

1) A principal estratégia para mitigar o risco da transmissão por COVID-19 é uma adequada ventilação dos espaços com ar novo proveniente do exterior, com recurso à ventilação natural ou mecânica. A ventilação tem um papel fundamental na diluição do ar interior junto das fontes emissoras e na remoção de agentes infeciosos, reduzindo a concentração e a dose inalada pelos ocupantes. Recomenda-se a abertura das janelas, cerca de 15 minutos antes da ocupação de uma sala, especialmente se esta foi ocupada por outras pessoas anteriormente, e a sua reabertura com periodicidade regular, mesmo em edifícios com ventilação mecânica.

2) Sempre que possível, o registo da entrada de ar novo das unidades de tratamento de ar deve ser ativado a $100 \%$ e a recirculação de ar deve ser desativada, mesmo quando existem filtros de ar no retorno, uma vez que estes raramente possuem a classificação HEPA (do inglês, high efficiency particulate arrestance) e, como tal, não são capazes de filtrar de forma eficaz as partículas virais. A recirculação de ar pode assim reintroduzir e distribuir partículas 
contaminantes de uns espaços para os outros que se encontrem interligados por redes de condutas ao mesmo equipamento.

3) O tempo de operação do sistema AVAC deve ser alargado, funcionando, se possível, 24 horas por dia e sete dias por semana, podendo durante o período de não ocupação funcionar com uma velocidade reduzida, de modo a diminuir a carga viral no interior do edifício. No entanto, pelo menos duas horas antes e depois da utilização do edifício o sistema deverá funcionar com a velocidade nominal. Por forma a evitar-se a via de transmissão fecal-oral, recomenda-se que o sistema de ventilação das instalações sanitárias funcione 24 horas por dia e sete dias por semana, que a janela se mantenha fechada para garantir a pressão negativa do espaço e que a tampa da sanita permaneça fechada durante a descarga.

4) A diferença de pressão entre áreas deve ser mantida, de forma a que o fluxo de ar se mova das áreas menos contaminadas para as áreas mais contaminadas.

5) A estratégia de limpeza do ar deve incluir unidades de tratamento de ar equipadas com filtros HEPA, uma vez que estes têm uma eficiência de remoção de partículas adequada para os aerossóis infeciosos.

Os edifícios de utilização pública como escolas, escritórios, espaços comerciais, restaurantes e ginásios, devido à sua elevada densidade de ocupação, podem levar a uma maior probabilidade de infeção por meio da transmissão aérea ou através de contatos diretos ou indiretos, apresentando um desafio especial para os seus proprietários e gestores. Por forma a responder a esta dificuldade, vários modelos e calculadoras têm sido desenvolvidos com o ob- jetivo de estimar o risco de infeção em espaços fechados perante diferentes condições e, assim, identificar medidas estruturais, de gestão ou sociais eficazes na redução do risco de infeção. ${ }^{17-20}$ Grande parte dessas metodologias são baseadas no modelo de Wells-Riley, que calcula a probabilidade de infeção em função do parâmetro quanta (vírus libertados), do tempo de exposição, da taxa de ventilação, do volume do espaço, entre outros fatores. ${ }^{21}$

Tendo por base um modelo atmosférico e um modelo de infeção, integrados na ferramenta de cálculo COVID Airborne Trasmission Estimator ${ }^{17}$ este trabalho vem comparar a eficácia de diferentes medidas de mitigação implementadas em espaços públicos interiores, mas cujo impacto no risco de infeção são ainda desconhecidos. Pretende assim contribuir para uma correta gestão dos edifícios públicos, com o objetivo de reduzir o risco de infeção. Esta ferramenta apresenta limitações que se prendem essencialmente com o facto de apenas considerar a transmissão por partículas inferiores a $10 \mu \mathrm{m}$, de não incluir a transmissão de curto alcance e de se basear em alguns pressupostos que são ainda incertos.

\section{MATERIAL E MÉTODOS}

O risco de infeção por SARS-CoV-2 foi estimado através do modelo de cálculo COVID Airborne Transmission Estimator versão 3.4.21 desenvolvido por J. L. Jimenez da Universidade de Colorado-Boulder. ${ }^{17} \mathrm{O}$ modelo é baseado na dispersão de partículas de aerossóis contendo SARS-CoV-2 em espaços fechados, e na acumulação e inalação destas partículas ao longo do tempo.

A metodologia de cálculo combina dois submodelos: um

Tabela 1 - Características de cada ambiente interior testado para a avaliação da probabilidade de infeção

\begin{tabular}{|c|c|c|c|c|c|}
\hline & Sala de aula & Sala de reunião & Restaurante & Super-mercado & Ginásio \\
\hline \multicolumn{6}{|l|}{ Características ambientais } \\
\hline Área $\left(\mathrm{m}^{2}\right)$ & 51 & 15 & 100 & 1500 & $\begin{array}{c}50^{*} \\
750^{* *}\end{array}$ \\
\hline Altura (m) & 2,8 & 2,8 & 3,0 & 3,5 & 2,8 \\
\hline Pressão (atm) & 0,95 & 0,95 & 0,95 & 0,95 & 0,95 \\
\hline Temperatura $\left({ }^{\circ} \mathrm{C}\right)$ & 18 & 22 & 22 & 22 & 22 \\
\hline Humidade relativa $(\%)$ & 60 & 55 & 55 & 55 & 55 \\
\hline$\left[\mathrm{CO}_{2}\right]$ exterior $(\mathrm{ppm})$ & 415 & 415 & 415 & 415 & 415 \\
\hline Taxa de decaimento do vírus $\left(\mathrm{h}^{-1}\right)^{28}$ & 1,01 & 1,55 & 1,55 & 1,55 & 1,55 \\
\hline Deposição nas superfícies $\left(\mathrm{h}^{-1}\right)^{(29,39)}$ & 0,24 & 0,24 & 0,24 & 0,24 & 0,24 \\
\hline \multicolumn{6}{|l|}{ Ocupantes e atividades } \\
\hline Taxa de inalação $\left(\mathrm{m}^{3} \mathrm{~h}^{-1}\right)^{31}$ & 0,52 & 1,10 & 1,10 & 1,38 & 3,30 \\
\hline Taxa de emissão de $\mathrm{CO}_{2}\left(\mathrm{Ls}^{-1}\right)^{32}$ & 0,0050 & 0,0060 & 0,0060 & 0,0085 & $\begin{array}{c}0,0178^{*} \\
0,0155^{\star *}\end{array}$ \\
\hline Taxa de exalação quanta $\left(\mathrm{h}^{-1}\right)^{18,26}$ & 16,0 & 18,7 & 14,8 & 10,9 & $\begin{array}{l}117,2^{*} \\
48,8^{* *}\end{array}$ \\
\hline \multicolumn{6}{|l|}{ COVID-19 na região em estudo } \\
\hline Prevalência da doença na população (\% $)^{24,25}$ & 2,8 & 2,8 & 2,8 & 2,8 & 2,8 \\
\hline Fração da população imune $(\%)^{24,27}$ & 5 & 5 & 5 & 5 & 5 \\
\hline
\end{tabular}

* aula de cycling; ** ginástica de aparelhos 
modelo atmosférico padrão, que assume que as partículas finas emitidas são rapidamente dispersas e misturadas num determinado volume ${ }^{22}$ e um modelo que quantifica o risco de infeção por aerossóis, o modelo Wells-Riley, ${ }^{23}$ tal como formulado por Miller et al. ${ }^{21}$ Segundo o modelo, a probabilidade de infeção é função: 1) da taxa de exalação da carga viral, dependente do número de pessoas infetadas e da atividade exercida; 2) da concentração da carga viral, que é função da taxa de exalação da carga viral, do volume e da taxa de ventilação do espaço e da existência de meios de filtração do ar; e 3) da taxa de inalação da carga viral que depende de fatores como a concentração da carga viral, da taxa de respiração associada à atividade exercida e da utilização e tipologia de máscaras selecionadas. ${ }^{17}$

Esta metodologia considera que o distanciamento social de dois metros é respeitado, não contempla a transmissão por gotículas nem por contacto, e assume que as partículas de aerossol estão igualmente distribuídas no espaço, o que significa que os valores da probabilidade de infeção são subestimados, principalmente nos espaços onde o distanciamento não é garantido. De qualquer forma esta ferramenta é bastante útil para a comparação de vários cenários e para o apoio à tomada de decisão.

No total, 242 cenários foram testados para cinco ambientes interiores: sala de aula, sala de reuniões, restaurante, supermercado e ginásio, cujas características principais são apresentadas na Tabela 1. Em cada ambiente foram simuladas várias condições como a utilização e eficácia de máscaras, a ventilação, a utilização de equipamentos que permitem uma assepsia do ar recorrendo a filtros HEPA, a densidade de ocupação e o tempo de permanência nos espaços. A descrição das condições de cada cenário, bem como a probabilidade de infeção associada, são apresentadas no Apêndice 1, Tabela S1 (Apêndice 1: https://www. actamedicaportuguesa.com/revista/index.php/amp/article/ view/15982/Apendice_01.pdf).

As simulações foram efetuadas tendo em conta a população de Lisboa e Vale do Tejo, sendo considerado o número de novos casos ocorridos, a percentagem de casos assintomáticos, a percentagem de hospitalizações e o número de casos que resultam em falecimento relativos a janeiro de $2021 . .^{24,25}$ Os valores de emissão quanta, utilizados em cada cenário e apresentados na Tabela 1, foram baseados nos trabalhos publicados por Buonnano. ${ }^{18,26} \mathrm{~A}$ vacinação não foi considerada no modelo pelo facto de ainda não estar disponível quando o trabalho foi realizado.

\section{RESULTADOS}

Nesta secção é apresentada a probabilidade de infeção estimada para 242 cenários testados em ambientes interiores de utilização pública, onde o risco é acrescido devido ao facto da densidade de ocupação ser elevada e, de muitas vezes, a ventilação ser ineficiente, não permitindo uma adequada renovação do ar (Apêndice 1, Tabela S1 em https://www.actamedicaportuguesa.com/revista/index.php/ amp/article/view/15982/Apendice_01.pdf).

\section{Salas de aula}

A ventilação é essencial para a remoção e diluição dos poluentes produzidos numa sala de aula. Na maior parte das escolas em Portugal, a ventilação é promovida por meios naturais, através da abertura das janelas, o que por vezes não assegura uma ventilação adequada dos espaços, principalmente durante os meses mais frios em que a abertura das janelas põe em causa o conforto térmico. Assim sendo, foram testados vários cenários com o objetivo de avaliar o impacto de diferentes níveis de abertura das janelas no risco de infeção individual diário, tendo como base uma sala de aula de $51 \mathrm{~m}^{2}$, com ocupação de 26 pessoas, para um dia com oito aulas de 50 minutos de duração, em que todos os ocupantes utilizam uma máscara social. A Fig. 1A mostra que o risco de infeção varia entre $2,53 \%$, para um cenário de janela fechada em que a renovação de ar $\left(0,3 \mathrm{~h}^{-1}\right)$ é apenas assegurada por processos de infiltração, e $0,92 \%$, para um cenário em que a janela se encontra aberta na sua totalidade permitindo uma renovação de ar de $7,2 \mathrm{~h}^{-1}$. Já a ventilação mecânica assegura uma renovação de ar de $5,5 \mathrm{~h}^{-1}$, garantindo assim o caudal regulamentar (situação equivalente à abertura das janelas a $75 \%$ ) e apresentando um risco de infeção de $1,10 \%$, isto é, um valor $56 \%$ inferior ao cenário sem ventilação mecânica com janela fechada. Foster e Kinzel ${ }^{33}$ obtiveram resultados semelhantes quando aplicaram o modelo Wells-Riley a uma sala de aula, tendo o risco de infeção reduzido $50 \%$ ao passar de um cenário de inexistência de ventilação para uma situação com ventilação mecânica.

Uma vez que o aumento da ventilação pode representar custos inviáveis para as escolas ou mesmo comprometer o conforto térmico, avaliou-se o impacte da instalação de purificadores de ar portáteis com filtros HEPA que possuem uma eficácia superior a 99,9\% para partículas de 0,3 $\mu \mathrm{m}$. Foram testados vários cenários em que a capacidade de renovação do ar pelo equipamento portátil variou entre 1 e $10 \mathrm{~h}^{-1}$, considerando por um lado que a sala de aula possui ventilação natural e tem as janelas fechadas e, por outro, que a sala de aula tem ventilação mecânica garantindo o caudal regulamentar $\left(5,5\right.$ horas $\left.^{-1}\right)$. A Fig. 1B mostra que a utilização destes equipamentos origina reduções de $72 \%$ na probabilidade de infeção, no caso da ventilação natural com as janelas fechadas. Nestas situações, a probabilidade de infeção pode alcançar níveis mais baixos do que os conseguidos em salas com sistemas de ventilação mecânica a operar com os caudais mínimos definidos por lei. De notar que a eficácia destes equipamentos depende da sua capacidade de renovação do ar. As simulações efetuadas mostram que os investimentos devem ser realizados apenas para equipamentos que promovam renovações do ar superiores a $5 \mathrm{~h}^{-1}$. No caso da ventilação mecânica, estes dispositivos também proporcionam uma redução da probabilidade de infeção, mas com magnitudes inferiores.

Em relação ao uso de máscara, testaram-se três cenários considerando sempre que a sala possui apenas ventilação natural e que as janelas se encontram fechadas (Fig. 1C). No primeiro cenário em que apenas o professor utiliza 
A

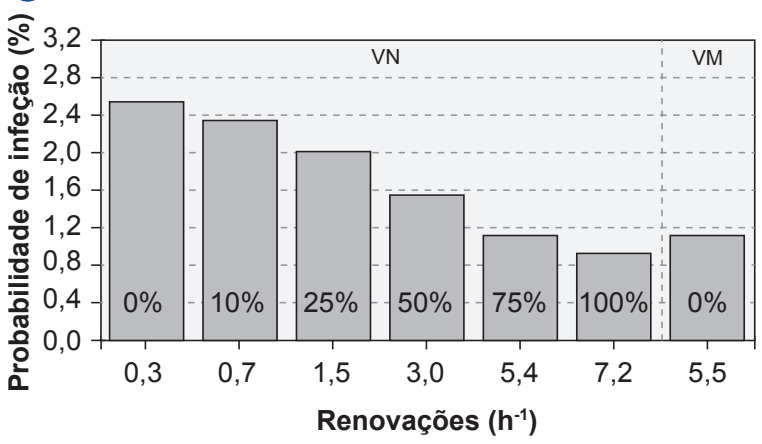

C

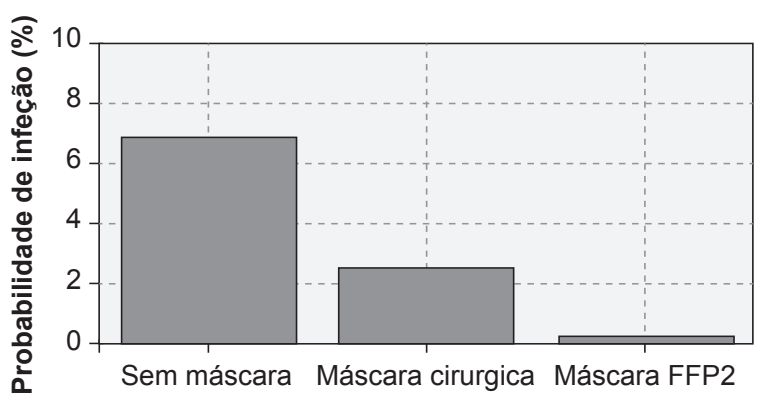

B
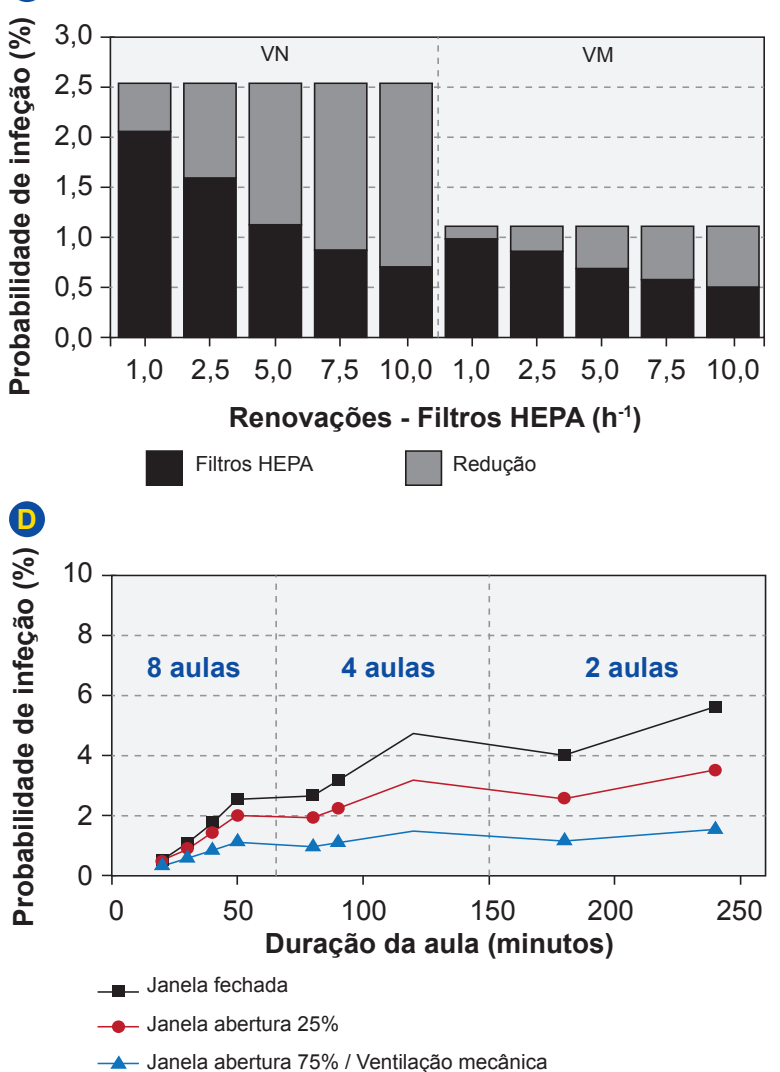

Figura 1 - Risco de uma pessoa ficar infetada estimado para vários cenários testados numa sala de aula: (A) variação da renovação de ar, considerando ventilação natural, com diferentes percentagens de abertura de janela, e ventilação mecânica com a renovação de ar regulamentar $\left(5,5 \mathrm{~h}^{-1}\right)$; (B) variação da renovação de ar nas unidades com filtros HEPA considerando ventilação natural com as janelas fechadas e ventilação mecânica com a renovação regulamentar; (C) utilização de máscara considerando ventilação natural e janela fechada; (D) variação da duração e do número de aulas e da ventilação.

VN: ventilação natural; VM: ventilação mecânica

uma máscara social (eficácia de redução de $50 \%$ na emissão e de $30 \%$ na inalação) ${ }^{34}$ verifica-se que a probabilidade de infeção é mais elevada $(6,84 \%)$ do que quando todos os alunos usam a mesma tipologia de máscara $(2,53 \%)$. Se todos os ocupantes da sala optarem por uma máscara KN95 ou FFP2, estima-se que poderá haver uma redução ainda maior, passando a probabilidade de infeção a ser de $0,07 \%$. Apesar de se poder alcançar uma eficácia superior nas máscaras KN95 e FFP2, foi selecionada apenas uma eficácia de $90 \%$, tanto na emissão como na inalação, por forma a considerar uma potencial colocação inadequada da máscara pela comunidade. Dai e Zhao ${ }^{35}$ utilizaram o modelo Wells-Riley para testar a utilização de máscaras cirúrgicas num espaço confinado com duas pessoas, estando uma infetada, e verificaram que se ambas usarem máscara a taxa de ventilação necessária para garantir uma probabilidade de infeção menor que $1 \%$ reduz entre 30 a $90 \mathrm{~m}^{3} \mathrm{~h}^{-1}$ para uma exposição de 0,25 h e entre 300 e 1000 $\mathrm{m}^{3} \mathrm{~h}^{-1}$ para uma exposição de três horas.

Por último, a Fig. 1D mostra que a duração e o número de aulas têm também uma influência importante na probabilidade de infeção, sendo que aulas mais curtas representam um risco inferior de infeção.

\section{Edifício de escritórios}

O risco de infeção foi estimado para uma sala de reuniões de $15 \mathrm{~m}^{2}$ de um edifício de escritórios, considerando que todos os ocupantes usam uma máscara social. A Fig. $2 \mathrm{~A}$ apresenta o impacto da ventilação no risco de infeção para uma ocupação de seis pessoas e mostra que o risco aumenta 1,6 vezes quando a renovação de ar é feita apenas por infiltração (ventilação natural, janelas fechadas; $0,25 \mathrm{~h}^{-1}$ ) em vez de cumprir o caudal regulamentar (ventilação mecânica; $2,7 \mathrm{~h}^{-1}$ ). Verifica-se também que o aumento do caudal de ar regulamentar em três vezes $\left(8,1 \mathrm{~h}^{-1}\right)$ diminui a probabilidade de infeção de $0,34 \%$ para $0,20 \%$.

Foi testada a utilização de equipamentos portáteis de purificação do ar utilizando filtros HEPA, com renovações de $10 \mathrm{~h}^{-1}$, tendo-se verificado uma redução da probabilidade de infeção, que atingiu $72 \%$ no caso da ventilação natural com as janelas fechadas. Estes resultados demostram que a utilização destes equipamentos pode ser uma solução muito eficaz, principalmente quando os espaços não estão equipados com ventilação mecânica e a renovação do ar não é eficaz.

A Fig. 2B mostra que o aumento do número de ocupantes e da duração das reuniões implica um incremento do risco de infeção. 


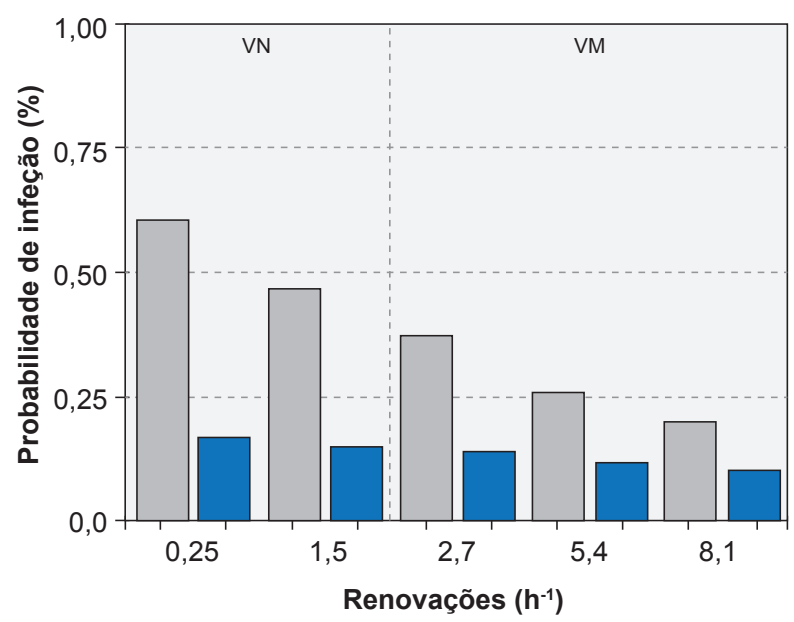

Sem filtro HEPA $\square$ Com filtro HEPA
B

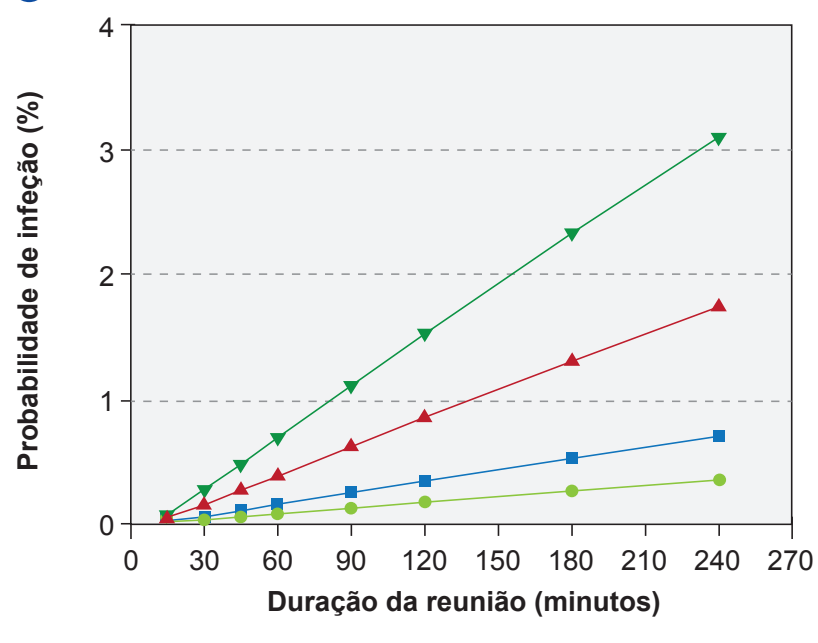

$-1,5 \mathrm{~m}^{2}$ ocupante $^{-1}$
$-2,5 \mathrm{~m}^{2}$ ocupante $^{-1}$
$-5,0 \mathrm{~m}^{2}$ ocupante $^{-1}$
$-7,5 \mathrm{~m}^{2}$ ocupante $^{-1}$

Figura 2 - Risco de uma pessoa ficar infetada para vários cenários testados numa sala de reuniões: (A) variação da renovação de ar, considerando ventilação natural com a janela fechada $\left(0,25 \mathrm{~h}^{-1}\right)$ e aberta $\left(1,5 \mathrm{~h}^{-1}\right)$ e ventilação mecânica considerando o caudal regulamentar (CR) $\left(2,7 \mathrm{~h}^{-1}\right), 2 \times C R\left(5,4 \mathrm{~h}^{-1}\right)$ e $3 \times \mathrm{CR}\left(8,1 \mathrm{~h}^{-1}\right)$ e existência de filtro HEPA; (B) variação da taxa de ocupação e da duração da reunião. VN: ventilação natural; VM: ventilação mecânica

A

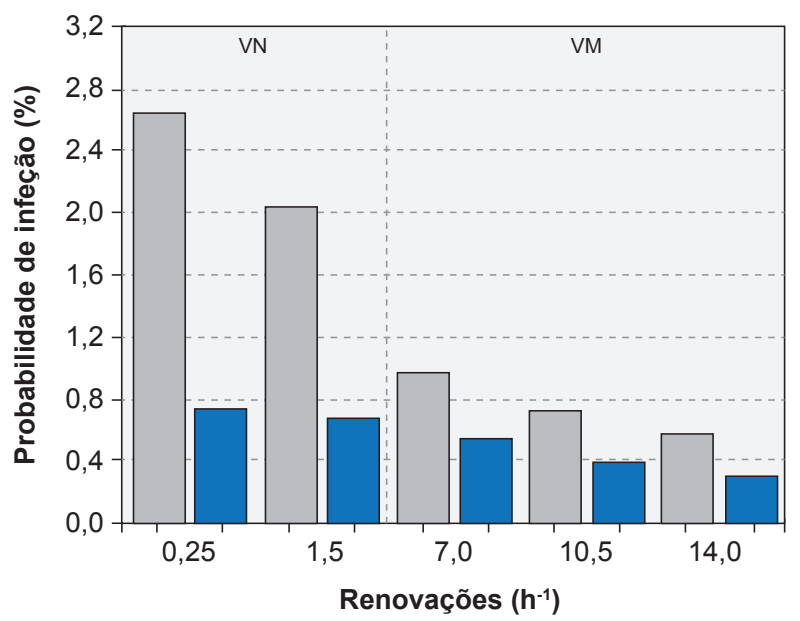

Sem filtro HEPA
B

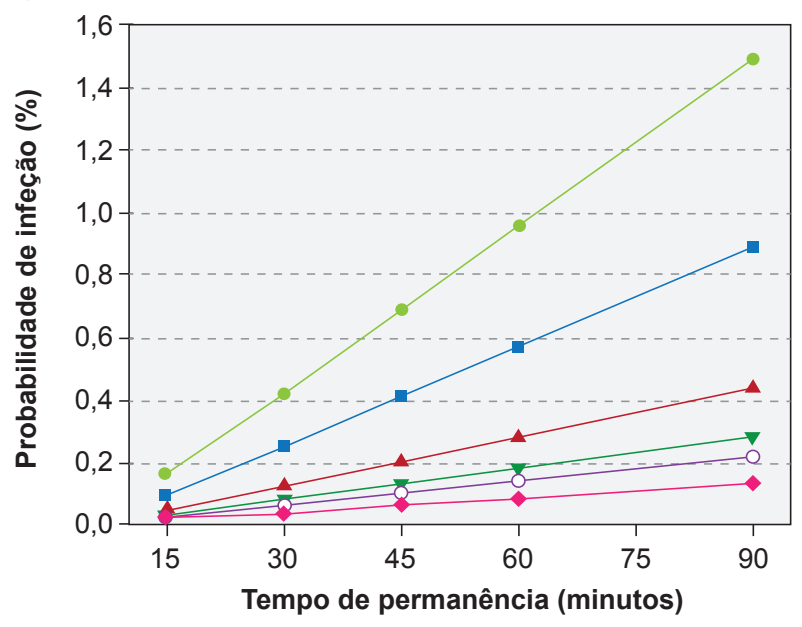

$-1,5 \mathrm{~m}^{2}$ ocupante ${ }^{-1}$
$-2,5 \mathrm{~m}^{2}$ ocupante $^{-1}$
$-5,0 \mathrm{~m}^{2}$ ocupante
-1
$-7,5 \mathrm{~m}^{2}$ ocupante
-1
-
$-10,0 \mathrm{~m}^{2}$ ocupante-1
$-15,0 \mathrm{~m}^{2}$ ocupante-1

Figura 3 - Risco de uma pessoa ficar infetada para vários cenários testados num restaurante: (A) variação da renovação de ar, considerando ventilação natural com a janela fechada $\left(0,25 \mathrm{~h}^{-1}\right)$ e aberta $\left(1,5 \mathrm{~h}^{-1}\right)$ e ventilação mecânica considerando o caudal regulamentar (CR) $\left(7 \mathrm{~h}^{-1}\right), 1,5 \times \mathrm{CR}\left(10,5 \mathrm{~h}^{-1}\right)$ e $2 \times \mathrm{CR}\left(14 \mathrm{~h}^{-1}\right)$ e existência de filtro HEPA; (B) variação da taxa de ocupação e do tempo de permanência VN: ventilação natural; VM: ventilação mecânica 


\section{Restaurantes}

Os restaurantes, para além de possuírem uma densidade de ocupação elevada, muitas vezes não têm uma ventilação adequada dos espaços e os ocupantes estão impossibilitados de usar a máscara. Estas condições aumentam o risco de infeção nestes locais.

A Fig. 3A mostra que a renovação do ar é determinante na probabilidade de infeção, podendo esta diminuir de $2,63 \%$, quando a renovação é apenas realizada por processos de infiltração $\left(0,25 \mathrm{~h}^{-1}\right)$, para $0,56 \%$ quando a renovação é de $14 \mathrm{~h}^{-1}$, o que corresponde a duas vezes o caudal regulamentar.

No caso dos restaurantes, pelo facto da área ser superior aos dois espaços anteriores, testou-se a utilização de equipamentos de purificação do ar portáteis com filtros HEPA e capacidade de renovação de ar de $10 \mathrm{~h}^{-1}$, apenas no caso da existência de ventilação natural. No caso do restaurante possuir ventilação mecânica, considerou-se a instalação de filtros HEPA no retorno da unidade de tratamento de ar já instalada. A Fig. 3A mostra a importância da utilização de filtros HEPA, sobretudo quando os restaurantes não possuem ventilação mecânica. Nesses casos pode atingir-se uma redução da probabilidade de infeção de $72 \%$, garantindo-se assim um risco de infeção inferior ao alcançado com a ventilação mecânica a operar com os caudais regulamentares.

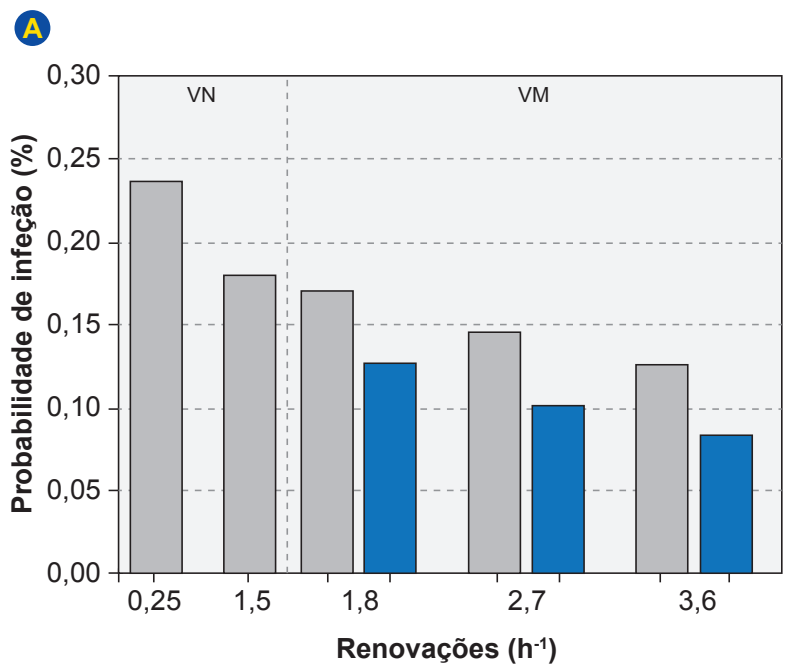

Sem filtro HEPA $\square$ Com filtro HEPA
A Fig. 3B mostra um aumento da probabilidade de infeção com o tempo de permanência, principalmente para densidades de ocupação elevadas.

\section{Supermercados}

Os supermercados apresentam um risco de infeção menor do que os três espaços referidos anteriormente. A Fig. 4A mostra que a probabilidade de infeção durante uma visita ao supermercado com uma duração de 60 minutos, utilizando uma máscara social, varia entre $0,13 \%$ para um valor de renovações de ar novo de 3,6 $\mathrm{h}^{-1}$ (corresponde ao dobro do caudal de ar regulamentar) e $0,24 \%$ para um cenário de ventilação natural onde as renovações se fazem apenas por infiltração $\left(0,25 \mathrm{~h}^{-1}\right)$. A utilização de filtros HEPA no retorno das unidades de tratamento de ar foi testada para os cenários de ventilação mecânica, tendo-se verificado uma diminuição da probabilidade de infeção entre $25,5 \%$ e $34,6 \%$, para renovações de $1,8 \mathrm{~h}^{-1}$ e $3,6 \mathrm{~h}^{-1}$, respetivamente.

A Fig. 4B mostra que num cenário de ventilação mecânica a operar com o caudal regulamentar, o tempo de permanência e a densidade de ocupação têm um impacto importante no risco de infeção. Para uma densidade de ocupação de 5,0 mºcup $^{-1}$ a probabilidade de infeção varia entre $0,02 \%$ para uma permanência de 15 minutos e $0,28 \%$ para 90 minutos, pelo que se aconselha a que as compras

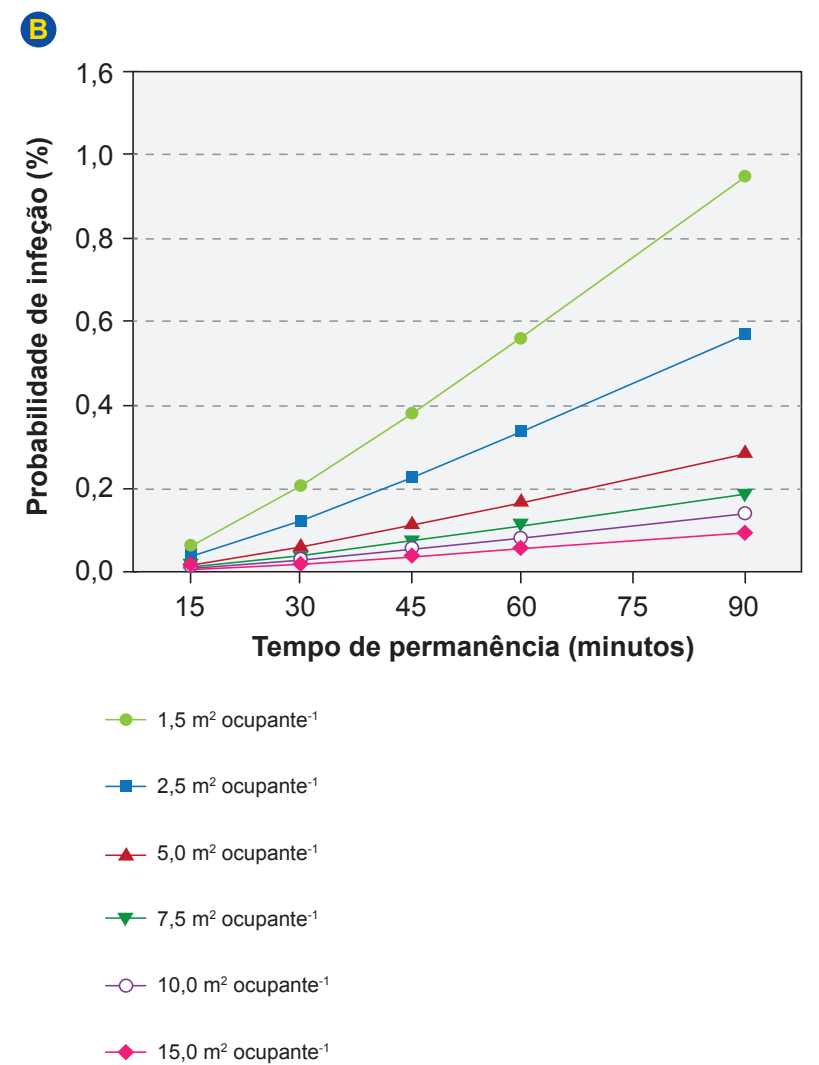


sejam realizadas o mais rapidamente possível. Para uma permanência de 60 minutos verifica-se que a probabilidade de infeção aumenta 10 vezes com a redução da densidade de $1,5 \mathrm{~m}^{2}$ ocup $^{-1}$ para $15 \mathrm{~m}^{2}$ ocup $^{-1}$. Vuorinen et a ${ }^{\beta 7}$ chegaram a conclusões semelhantes, mostrando que a exposição durante a visita a um supermercado, mesmo com densidades de ocupação relativamente elevadas, é reduzida. Estes autores verificaram que existe uma correlação linear entre a probabilidade de inalação de aerossóis e a densidade de ocupação, mas que essa probabilidade aumenta mais rapidamente em função do tempo de permanência no supermercado, aconselhando assim que a frequência e a duração das visitas ao supermercado sejam limitadas e que sejam evitadas as horas de elevada ocupação.

\section{Ginásios}

A Fig. 5A compara a probabilidade de infeção para uma aula de cycling (quanta igual a $117,2 \mathrm{~h}^{-1}$ ) realizada numa sala com $50 \mathrm{~m}^{2}$, com um treino realizado com máquinas (quanta igual a 48,8 $\mathrm{h}^{-1}$ ) num espaço com $750 \mathrm{~m}^{2}$. Esta comparação mostra que nos ambientes com renovação de ar apenas por infiltração o risco é muito superior para a aula de cycling $(23,1 \%)$ do que para o treino com máquinas realizado no open space do ginásio $(2,7 \%)$. Verifica-se que na aula de cycling a probabilidade de infeção continua elevada $(4,72 \%)$, apesar da ventilação mecânica que garante os caudais regulamentares.
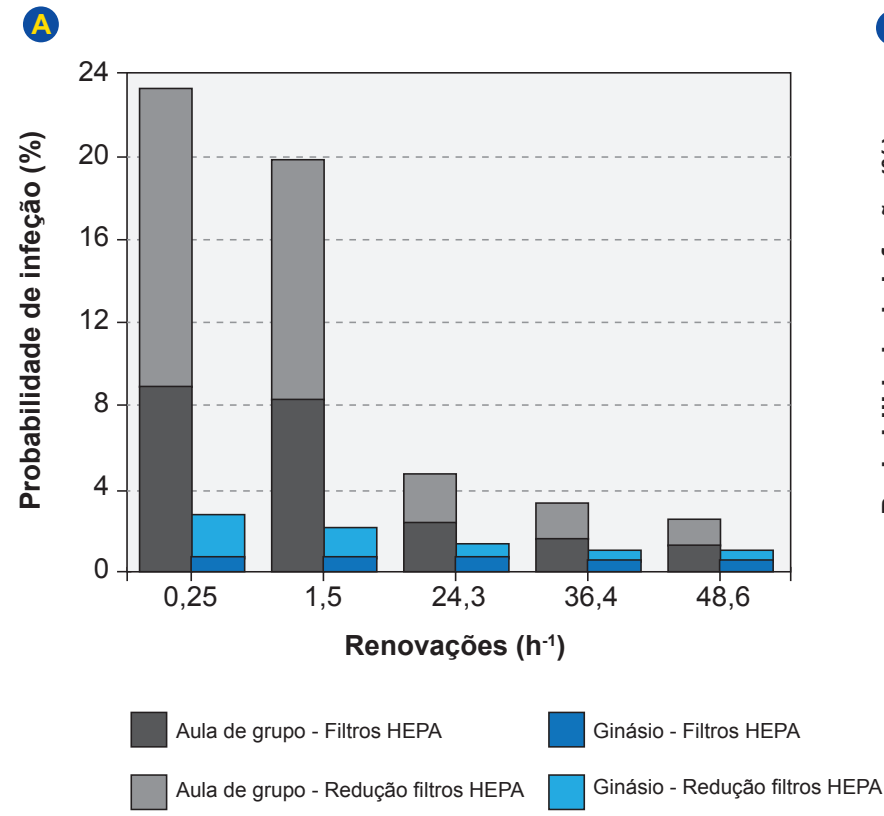

Dever-se-á, portanto, recorrer a unidades de tratamento de ar equipadas com filtros HEPA para as quais se estimaram reduções de $61 \%$ no caso da ventilação natural (equipamento portátil com renovações de $10 \mathrm{~h}^{-1}$ ) e de $50 \%$ para a ventilação mecânica (caso se instalem filtros HEPA no retorno da UTA).

A Fig. 5C, referente a uma aula de cycling de 45 minutos com ventilação mecânica que garante o caudal regulamentar, mostra que a probabilidade de infeção depende em grande parte da densidade de ocupação e da duração da aula.

\section{DISCUSSÃO}

Os diversos cenários estudados neste trabalho permitiram estimar o impacto da implementação de medidas de gestão ambiental na diminuição da probabilidade de contágio viral em edifícios de utilização publica.

Os resultados apresentados ao longo do estudo evidenciam a importância de uma adequada ventilação em ambientes fechados, sendo possível concluir que a introdução de ar exterior no interior dos espaços, através de meios naturais ou mecânicos, é fundamental para garantir uma adequada qualidade do ar interior e uma maior segurança das pessoas. Verificou-se uma maior probabilidade de infeção em ambientes com maior densidade de ocupação, e tempos de permanência mais elevados, verificando-se assim que a utilização dos espaços é possível, desde que

B

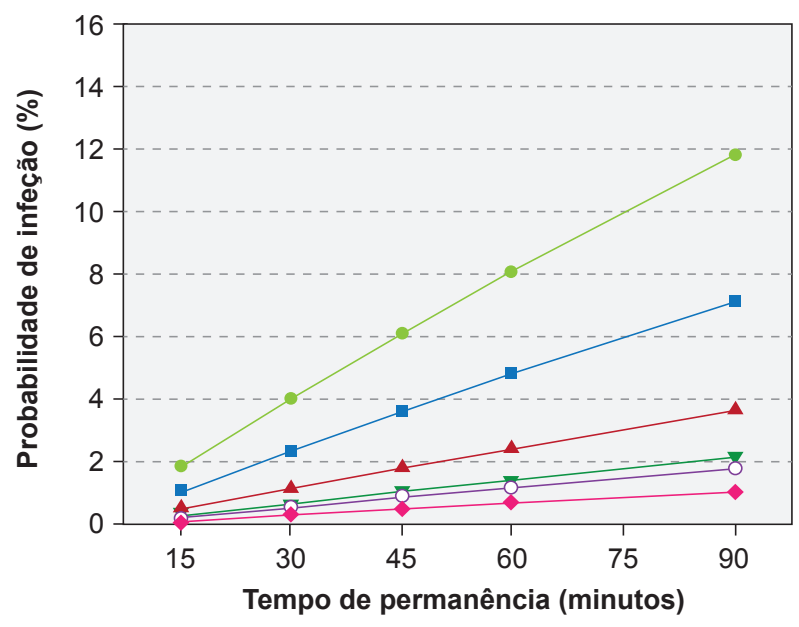

$$
\begin{aligned}
& \text { - } 1,5 \mathrm{~m}^{2} \text { ocupante }^{-1} \\
& -2,5 \mathrm{~m}^{2} \text { ocupante }{ }^{-1} \\
& -5,0 \mathrm{~m}^{2} \text { ocupante } \\
& \neg-7,5 \mathrm{~m}^{2} \text { ocupante } \\
& - \text { - } 10,0 \mathrm{~m}^{2} \text { ocupante }{ }^{-1} \\
& \downarrow 15,0 \mathrm{~m}^{2} \text { ocupante }^{-1}
\end{aligned}
$$

Figura 5 - Risco de uma pessoa ficar infetada para vários cenários testados num ginásio: (A) variação da renovação de ar, considerando ventilação natural com a janela fechada $\left(0,25 \mathrm{~h}^{-1}\right)$ e aberta $\left(1,5 \mathrm{~h}^{-1}\right)$, ventilação mecânica considerando o caudal regulamentar $(C R)(24,3$ $\left.\mathrm{h}^{-1}\right), 1.5 \times \mathrm{CR}\left(36,4 \mathrm{~h}^{-1}\right)$ e $2 \times \mathrm{CR}\left(48,6 \mathrm{~h}^{-1}\right)$ e a utilização de filtro HEPA. (B) variação da taxa de ocupação e do tempo de permanência. 
com um menor número de pessoas no seu interior e por períodos de permanência curtos.

Os resultados mostraram que a duração e o número de aulas nas escolas têm uma influência importante na probabilidade de infeção. Em algumas escolas tem-se verificado o aumento da duração das aulas para evitar o contacto entre os alunos durante os intervalos e para reduzir o tempo de permanência dos alunos nas escolas. No entanto, verifica-se que aulas mais curtas representam um risco inferior de infeção. Nos escritórios, as reuniões presenciais deverão ser reduzidas ao mínimo e, quando tal não é viável, deverão ser realizadas com o menor número possível de pessoas e durante pouco tempo. Vuorinen et a ${ }^{\beta 7}$ também aconselham o trabalho remoto e a permanência nos escritórios por curtos períodos de tempo. Estes investigadores estudaram a importância da velocidade de deslocação dos indivíduos num determinado local, através de modelação com Monte Carlo, e concluíram que quando as pessoas permanecem paradas durante oito a 10 horas por dia, como acontece nos edifícios de escritório, o risco de ficar infetada é superior do que noutros espaços públicos como escolas e supermercados. Verifica-se também um aumento da probabilidade de infeção nos restaurantes, em resultado da densidade de ocupação e do tempo de permanência. O risco de um tempo de permanência de 15 minutos, equivalente a atividades de take-away, diminui significativamente, apresentando probabilidades de infeção inferiores a 0,2\%. Segundo Vuorinen et al, ${ }^{37}$ a redução da densidade de ocupação em metade pode aumentar o tempo de exposição critico em duas vezes. Assim como nos restaurantes, o risco associado à utilização dos ginásios é acrescido devido ao facto dos utilizadores não usarem máscaras. Para além disso, nestes espaços a taxa de respiração e a taxa de exalação quanta são bastante incrementadas, aumentando a probabilidade de infeção. Mittal et a ${ }^{20}$ estimaram o impacto da atividade física no risco de transmissão e concluíram que em ginásios o risco de transmissão pode ser 200 vezes superior relativamente a outros espaços em que a atividade é sedentária. Os resultados obtidos para estes espaços mostraram que o recurso a unidades de tratamento de ar equipadas com filtros HEPA pode diminuir bastante o risco de infeção.

Deve ser realçado que o modelo utilizado possui algumas limitações que podem contribuir para a subvalorização dos valores estimados face à realidade:

1) O modelo assume o distanciamento físico de dois metros, sendo que este afastamento não consegue ser garantido em alguns dos espaços estudados.

2) O modelo exclui a transmissão por gotículas e por contacto.

3) O modelo apenas considera a transmissão por partículas inferiores a $10 \mu \mathrm{m}$, mesmo havendo evidências que partículas até $100 \mu \mathrm{m}$ podem permanecer no ar durante períodos que variam entre alguns minutos a horas $^{9}$ e que, por isso, podem percorrer distâncias consideráveis.

4) O modelo considera que os aerossóis e o risco de infeção estão uniformemente distribuídos no espaço, quando na realidade é sabido que existe um cone de diluição dos aerossóis exalados que origina concentrações inversamente proporcionais ao quadrado da distância e à velocidade, ${ }^{39}$ o que resulta num maior risco na proximidade da pessoa infetada.

5) O modelo baseia-se em pressupostos que são ainda incertos, como por exemplo a quantidade de vírus infeciosos emitida por uma pessoa infetada.

6) Deve ser ainda referido que a eficácia das diferentes máscaras utilizadas pelo modelo são uma aproximação baseada em trabalhos anteriores. No entanto, existe uma grande variabilidade dessa eficácia devido aos diferentes materiais utilizados e à forma como a máscara é utilizada. Konda et $a^{\beta 6}$ verificaram que a eficácia de filtração para vários tecidos varia entre $5 \%$ e $80 \%$ (para partículas de dimensão menor do que $300 \mathrm{~nm}$ ) e entre 5\% e 95\% (para partículas de dimensão maior do que $300 \mathrm{~nm}$ ), sendo que estes valores aumentam quando são usadas várias camadas de tecidos combinando diferentes materiais. A eficácia de filtração dos híbridos (como algodão-seda, algodão-chiffon, algodão-flanela) pode ser superior a $80 \%$ (para partículas de dimensão menor do que $300 \mathrm{~nm}$ ) e maior do que $90 \%$ (para partículas de dimensão maior do que 300 $\mathrm{nm}$ ). Estes autores verificaram também que o ajuste impróprio da máscara pode resultar numa diminuição de mais de $60 \%$ na eficácia de filtragem.

Apesar destas limitações, este modelo é considerado como uma ferramenta semi-quantitativa, muito útil para comparar diferentes opções de comportamento das pessoas e de gestão dos edifícios e para identificar os principais fatores de risco.

Por forma a melhorar os resultados gerados por este modelo, será necessário incluir num trabalho futuro não só os efeitos de proximidade, como também diferentes parâmetros que influenciam a física dos fluxos de ar, como o tipo de ventilação, os padrões de distribuição do ar, a geometria dos espaços, o movimento das pessoas, e outros parâmetros que afetam a viabilidade do vírus.

\section{CONCLUSÃO}

A atual situação de pandemia obrigou a um confinamento e distanciamento das pessoas, sendo uma forte preocupação de todos o regresso a uma atividade 'normal' de forma mais segura, uma vez que grande parte do tecido económico em Portugal é alicerçado em espaços fechados.

Este estudo avaliou o impacto de vários fatores na probabilidade de infeção, tais como o tipo de ventilação, a densidade de ocupação, o tempo de permanência nos espaços e a utilização de máscara, com o objetivo de identificar práticas que permitam reduzir a probabilidade de infeção no interior dos edifícios.

Verificou-se que a redução do risco de infeção passa pela adoção de medidas relacionadas com os sistemas de ventilação dos edifícios, como o aumento da ventilação dos espaços com ar exterior e a utilização de sistemas de filtragem do ar mais eficientes, em conjunto com medidas comportamentais como a utilização de máscara e a 
diminuição do tempo de permanência em espaços com elevada densidade de ocupação. Consequentemente, para além das medidas que já estão disseminadas, como a utilização de máscara, distância social e higiene pessoal, é essencial haver diretrizes claras para os gestores dos edifícios sobre ventilação, filtragem e rotinas de ocupação que permitam proteger os utilizadores dos espaços fechados.

Dada a complexidade dos fenómenos e do grande número de fatores envolvidos, não é surpreendente que dois anos mais tarde continuem a existir questões fundamentais por esclarecer. Estas questões envolvem as mais diversas áreas desde a biomedicina, epidemiologia, virologia, saúde pública, dinâmica dos fluidos, física dos aerossóis, psicologia dos comportamentos, políticas publicas, etc. O modelo utilizado neste trabalho, apesar de utilizar conceitos complexos e multidisciplinares pretende, de uma forma simples e intuitiva, informar os decisores políticos, os profissionais nas diferentes áreas de atuação e a população em geral sobre os principais fatores associados à disseminação da doença, e sobre as estratégias de redução do risco de infeção. Este estudo identificou limitações, relativas ao modelo, que tendem a subestimar os valores da probabilidade de infeção. Deste modo, este método dever-se-á considerar como uma ferramenta semi-quantitativa cuja mais valia é a comparação do impacto de diferentes medidas de mitigação.

\section{REFERÊNCIAS}

1. World Health Organization. Numbers at a glance, 2021. [consultado 2021 set 24]. Disponível em: https://www.who.int/emergencies/ diseases/novel-coronavirus-2019.

2. World Health Organization. Infection prevention and control of epidemic - and pandemic - prone acute respiratory infections in health care. Geneva: WHO; 2014. [consultado 2021 mai 14]. Disponível em: https:// apps.who.int/iris/bitstream/handle/10665/112656/9789241507134_eng. pdf?sequence=1.

3. Correia G, Rodrigues L, Gameiro da Silva M, Goncalves T. Airborne route and bad use of ventilation systems as non-negligible factors in SARS-CoV-2 transmission. Med Hypoth. 2020;141:109781.

4. Morawska L, Cao J. Airborne transmission of SARS-CoV-2: the world should face the reality. Environ Int. 2020;13:105730.

5. Morawska L, Tang JL, Bahnfleth W, Bluyssen PM, Boerstra A, Buonanno $\mathrm{G}$, et al. How can airborne transmission of COVID-19 indoors be minimised? Environ Int. 2020;142:105832.

6. Stadnytskyi V, Bax CE, Bax A, Anfinrud P. The airborne lifetime of small speech droplets and their potential importance in SARS-CoV-2 transmission. Proc Natl Acad Sci. 2020;117:11875-7.

7. Hamner L, Dubbel P, Capron I, Ross A, Jordan A, Lee J, et al. SARSCoV-2 attack rate following exposure at a choir practice. Morb Mortal Wkly Rep High. 2020;69:606-10.

8. Zhang S, Diao MY, Yu W, Pei L, Lin Z, Chen D. Estimation of the reproductive number of novel coronavirus (COVID-19) and the probable outbreak size on the Diamond Princess cruise ship: a data-driven analysis. Int J Infect Dis. 2020;93:201-4.

9. Prather KA, Marr LC, Schooley RT, McDiarmid MA, Wilson ME, Milton DK. Airborne transmission of SARS-CoV-2. Science. 2020;370:303-4.

10. Tang JW, Bahnfleth WP, Bluyssen PM, Buonanno G, Jimenez JL, Kurnitski J. Dismantling myths on the airborne transmission of severe acute respiratory syndrome coronavirus-2 (SARS-CoV-2). J Hosp Infect. 2021;110:89-96.

11. Chen W, Zhang N, Wei JJ, Yen HL, Li Y. Short-range airborne route dominates exposure of respiratory infection during close contact. Build Environ. 2020;176:106859.

12. Qian H, Miao T, Liu L, Zheng XH, Luo DT, Li YG. Indoor transmission of SARS-CoV-2, Indoor Air. 2020;00:1-7.

13. Riediker M, Tsai D-H. Estimation of viral aerosol emissions from

\section{CONTRIBUTO DOS AUTORES}

Ambos os autores contribuíram de igual forma para a conceção do artigo, revisão da literatura e redação do manuscrito.

\section{PROTEÇÃO DE PESSOAS E ANIMAIS}

Os autores declaram que os procedimentos seguidos estavam de acordo com os regulamentos estabelecidos pelos responsáveis da Comissão de Investigação Clínica e Ética e de acordo com a Declaração de Helsínquia da Associação Médica Mundial atualizada em 2013.

\section{CONFIDENCIALIDADE DOS DADOS}

Os autores declaram ter seguido os protocolos do seu centro de trabalho acerca da publicação de dados.

\section{CONFLITOS DE INTERESSE}

Os autores declaram não ter conflitos de interesses relacionados com o presente trabalho.

\section{FONTES DE FINANCIAMENTO}

Este estudo foi parcialmente financiado pela Fundação para a Ciência e Tecnologia através do projeto UIDB/04349/2020+UIDP/04349/2020 e pelo programa LIFE da União Europeia através do projeto LIFE Index-Air (LIFE 15ENV/PT/000674).

simulated individuals with asymptomatic to moderate coronavirus disease 2019. JAMA Network Open. 2020;3:e2013807.

14. Dai H, Zhao B. Association of the infection probability of COVID19 with ventilation rates in confined spaces. Build Simul. 2020;13:1321-7.

15. Chirico F, Sacco A, Bragazzi NL, Magnavita N. Can air-conditioning systems contribute to the spread of SARS/MERS/COVID-19 infection? Insights from a rapid review of the literature. Int $\mathrm{J}$ Environ Res Public Health. 2020;17:6052.

16. Guo M, Xu P, Xiao T, He R, Dai M, Miller SI. Review and comparison of HVAC operation guidelines in different countries during the COVID-19 pandemic. Build Environ. 2021;187:107368.

17. Jimenez JL. COVID-19 Aerosol transmission estimator. [consultado 2021 jan 1]. Disponível em: https://tinyurl.com/covid-estimator.

18. Buonanno G, Stabile L, Morawska L. Estimation of airborne vira emission: quanta emission rate of SARS-CoV-2 for infection risk assessment, Environ Int. 2020;141:105794.

19. Dai H, Zhao B. Association of the infection probability of COVID-19 with ventilation rates in confined spaces, Build Simul. 2020;13:1321.

20. Mittal R, Meneveau C, Wu W. A mathematical framework for estimating risk of airborne transmission of COVID-19 with application to face mask use and social distancing. Phys Fluids. 2020;32:101903.

21. Miller SL, Nazaroff W, Jimenez JL, Boerstra A, Buonanno G, Dancer SJ, et al. Transmission of SARS-CoV-2 by inhalation of respiratory aerosol in the Skagit Valley Chorale superspreading event. Indoor Air. 2021;31:314-23.

22. Jacob DJ. Introduction to atmospheric chemistry. New Jersey: Princeton University Press; 1999.

23. Riley E, Murphy G, Riley R. Airborne spread of measles in a suburban elementary school. Am J Epidemiol. 1978;107:421-32.

24. Direção Geral da Saúde. Ponto da Situação em Portugal, 2021 [consultado 2021 jan 1]. Disponível em: https://covid19.min-saude.pt/ ponto-de-situacao-atual-em-portugal/.

25. Institute for Health Metrics and Evaluation. COVID-19 projections, 2021. [consultado 2021 jan 1]. Disponível em: https://covid19.healthdata.org/ portugal?view=cumulative-deaths $\&$ tab=trend.

26. Buonanno G, Morawska L, Stabile L. Quantitative assessment of the risk of airborne transmission of SARS-CoV-2 infection: prospective and retrospective applications. Environ Int. 2020;145:106112. 
27. Hansen C, Michlmayr D, Gubbels S, Mølbak K, Ethelberg S. Assessment of protection against reinfection with SARS-CoV-2 among 4 million PCRtested individuals in Denmark in 2020: a population-level observational study. Lancet. 2021;397:1204-12.

28. Department of Homeland Security. Estimated surface decay of SARSCoV-2 (virus that causes COVID-19) on surfaces under a range of temperatures, relative humidity, and UV Index. SARS-CoV-2 Surface Decay Calculator, 2021. [consultado 2021 jan 1]. Disponível em: https:// www.dhs.gov/science-and-technology/sars-calculator.

29. Thatcher TL, Laia AC, Moreno-Jackson R, Sextro RG, Nazaroff WW. Effects of room furnishings and air speed on particle deposition rates indoors. Atmos Environ. 2002;36:1811-9.

30. Chatoutsidou SE, Lazaridis M. Assessment of the impact of particulate dry deposition on soiling of indoor cultural heritage objects found in churches and museums/libraries. J Cult Herit. 2019;39:221-8.

31. United States Environmental Protection Agency. Exposure factors handbook 2011 Edition (Final Report). Washington: USEPA; 2011.

32. Persily $A$, de Jonge $L$. Carbon dioxide generation rates for building occupants. Indoor Air. 2017;27:868-79.

33. Foster A, Kinzel M. Estimating COVID-19 exposure in a classroom setting: a comparison between mathematical and numerical models.
Phys Fluids. 2021;33:021904.

34. Davies A, Thompson KA, Giri K, Kafatos G, Walker J, Bennett A. Testing the efficacy of homemade masks: would they protect in an influenza pandemic? Disaster Med Public Health Prep. 2013;7:413-8.

35. Dai H, Zhao B. Association of the infection probability of COVID-19 with ventilation rate in confined spaces. Build Simul. 2020;13:1321.

36. Konda A, Prakash A, Moss G, Schmoldt M, Grant G, Guha S. Aeroso filtration efficiency of common fabrics used in respiratory cloth masks. ACS Nano. 2020;14:6339-47.

37. Vuorinen V, Aarnio M, Alava M, Alopaeus V, Atanasova N, Auvinen M, et al. Modelling aerosol transport and virus exposure with numerica simulations in relation to SARS-CoV-2 transmission by inhalation indoors. Saf Sci. 2020;130:104866.

38. Peng Z, Jimenez JL. Exhaled $\mathrm{CO}_{2}$ as a COVID-19 infection risk proxy for different indoor environments and activities. Environ Sci Technol Lett. 2021:8:392-7.

39. Poydenot F, Abdourahamane I, Caplain E, Der S, Haiech J, Jallon A et al Risk assessment for long and short range airborne transmission of SARS CoV-2, indoors and outdoors, using carbon dioxide measurements, medRxiv. 2021.05.04.21256352. doi: 10.1101/2021.05.04.21256352 